\title{
Effect of Aspect ratio and Volume Fraction of Steel Fibers in Strength Properties of Geopolymer Concrete
}

\author{
Prabu Baskar, Kumutha Rathinam, Vijai Kanagarajan
}

\begin{abstract}
In this present study, a trail has been conducted to examine the influence of dissimilar aspect ratio and diverse volume fractions of steel fibers in GPC under various curing exposures on the fresh and mechanical properties. Meanwhile, the major strength performance of concrete such as compressive strength, split tensile, flexural, workability and microstructure properties were also studied. From the test results, it was revealed that in the heat curing method, there was just a low augmentation in the compressive strength at 28 years old days when compared with ambient curing condition. Then again, a radical increment in the compressive strength was recognized at 3 days on account of thermal curing because of the elevated polymerization process. The microstructure investigation illustrated that the $F A$ and GGBS particles reacted with the alkaline activator solution and formed a denser structure in the heat curing process when compared with the room-cured specimens because of the unreacted particles present in it. The $X$ ray diffraction pattern shows that the geopolymer particles are crystalline in nature. It was observed that the strength properties were increases with the augment in aspect ratio (Ar) and high percentage volume of steel fibers.
\end{abstract}

Keywords: Fibers, Mechanical properties, Microstructure, Polymerization.

\section{INTRODUCTION}

Geopolymer is a new class high-performance inorganic binder which attracts the researchers in recent years as a substitute material for Ordinary Portland Cement (OPC). Professor Davidovits first coined the term geopolymer in the 1970s, and he discovered that geopolymers are the binder material in amorphous natured three-dimensional aluminosilicates [6,31]. It is a new binder material which reveals the better durability, freeze-thaw resistance, chemical resistance, abrasion resistance, low chloride diffusion rate and thermal stability than OPC [29]. Also, it shows very little confrontation to cracking owing to their enormous brittle, ceramics like nature [22]. Geopolymer binders can be produced by combining alumino-silicate reactive materials such as fly ash, metakaolin which is strong in alkaline solution $(\mathrm{NaOH}$ and $\mathrm{KOH})$ and then cured at ambient temperature [31]

The base material used to manufacture geopolymer concrete primarily arrives from industrial by-products such as rice husk ash (RHA),fly ash, Bottom ash and Ground Granulated Blast furnace Slag (GGBS) [19]. Recent research shows that there is feasibility of using industrial

\footnotetext{
Revised Manuscript Received on 14, October 2019.

Prabu Baskar, Civil Engineering, Sona College of Technology, Salem, Tamilnadu, India. (Email: prabu99522@gmail.com)

Dr.Kumutha Rathinam, Civil Engineering, Sethu Institute of Technology, Kariapatti, Tamilnadu, India. (Email: kumuthar@yahoo.co.in)

Dr.Vijai Kanagarajan, Civil Engineering, St. Joseph's College of Engineering, OMR, Chennai, India. Email: vijai_me@yahoo.co.in
}

waste matter as a partial substitute for commercially available alkaline solutions [7]. Geopolymer concrete is an appropriate material for structural applications, and it contains the design procedures in the present standards and codes to design the structural members with fly ash-based GPC [14]. Hardjito et al. [7] experimented that curing of samples at different heat condition acting an imperative role in the process of geopolymerization in GPC. They reported that the increase in curing temperature at higher rate resulted in a rapid rate of the geopolymerization process. It is also documented that prolonged curing time yields better compressive strength in geopolymer concrete because of its geopolymerization process [2, 21]. The earlier reports suggested that curing temperature from $60^{\circ} \mathrm{C}$ to $70^{\circ} \mathrm{C}$ increases the compressive strength, but beyond $70^{\circ} \mathrm{C}$ of curing condition consequence in lower compressive strength.

Fly ash (FA) which higher amount in silica and alumina is one of the industrial pozzalonic by-product materials which can be used as a binder material in concrete because of its abundant quantity available worldwide, and many researchers have proven its enhanced durability, mechanical properties and microstructural compositions $[3,5,14,15,17,28]$. Previous research shows that there is degradation in compressive strength by replacing more than $50 \%$ of fly ash in concrete. On the other hand, geopolymer produced with $100 \%$ alternate of fly ash resulted in deferred setting time and other limitations such as curing methods.

The adding together of fibers with concrete can enhance the strength characteristics of the resulting product. Nath et al. [20] reported that cementitious materials are commonly brittle and are intrinsically weak in resisting the tensile forces in concrete. The propagation of cracks generally causes immediate failure caused by a lower amount of tensile forces. Incorporating steel reinforcement in concrete resists the tensile forces in the cementitious materials. The addition of fibers with concrete works on a related premise whereby fibers take action to pass on the tensile forces athwart the cracks.

Fiber-reinforced concrete has been engaged in different cementitious materials to enhance the impact characteristics, flexural behavior, and toughness and to change failure mode. Different researches were performed using different types and diverse volume portions of strands so as to study their result on the exposition of the binder in the way of leading the durability and strength tests.

Islam et al. [14] investigated the properties and impact confrontation of steel fiber reinforced LWGPC and they concluded that adding together of steel fibers 


\section{EFFECT OF ASPECT RATIO AND VOLUME FRACTION OF STEEL FIBERS IN STRENGTH PROPERTIES OF GEOPOLYMER CONCRETE}

improved the tensile strength and bending strength by $38 \%$ and $44 \%$ correspondingly when compared to plain concrete, also fiber added concrete samples showed excellent impact confrontation when evaluated with plain concrete specimens. Ganesan et al. [6] investigated on performance of Non-Reinforced and fiber-reinforced geopolymer in durability aspects. The results showed that FRGPC and plain GPC yields better properties when match up to with conventional concrete. Moreover, the toting up of steel fibers in concrete resulted in concerning durability performances. The problems persist in producing geopolymer concrete are setting time and curing methods. In order to prevent this problem, endeavor has been prepared to make the geopolymer concrete with fly ash, GGBS, and steel fibers in ambient temperature.

This present research aims to examine the fresh, mechanical and microstructural characteristics of FRGPC with Steel fibers in various aspect ratios (Ar) and different volume fractions (Vr). The fresh property includes workability by compaction factor test and mechanical properties and impact strength was also studied. SEM analysis was executed to synthesize the characterization of GPC specimens under ambient and heat curing.

\section{MATERIALS CHARACTERIZATION}

Fly ash (Class F), which is confirming to standard IS 3812 - 2003 [13] was gotten from Thermal Power Station situated in a mettur in Tamil Nadu, India. GGBS was bought from Quality Polytech, Mangalore, India. Table I displays the compound organization of FA and GGBS. The particular gravity and fineness of fly ash were 2.46 and 7.62 separately. GGBS has specific gravity and fineness of 2.91 and 3.11 individually. Figure 1 and 2 illustrates the morphology of class F FA and GGBS utilized in this examination. The soluble arrangement was a blend of $\mathrm{Na}_{2} \mathrm{SiO}_{3}$, and $10 \mathrm{M} \mathrm{NaOH}$ was utilized.

Table- I: Chemical compositions of GGBS and FA

\begin{tabular}{|l|l|l|l|l|l|l|}
\hline $\begin{array}{l}\text { Eleme } \\
\text { nt as } \\
\text { Oxide }\end{array}$ & $\mathrm{SiO}_{2}$ & $\begin{array}{l}\mathrm{Al}_{2} \mathrm{O} \\
3\end{array}$ & $\begin{array}{l}\mathrm{Fe}_{2} \mathrm{O} \\
3\end{array}$ & $\mathrm{CaO}$ & $\begin{array}{l}\mathrm{Mg} \\
\mathrm{O}\end{array}$ & $\begin{array}{l}\mathrm{LO} \\
\mathrm{I}\end{array}$ \\
\hline FA & $\begin{array}{l}54.8 \\
9\end{array}$ & 15.31 & 21.83 & 0.12 & 2.51 & 0.7 \\
\hline GGBS & $\begin{array}{l}42.2 \\
1\end{array}$ & 21.12 & 7.32 & 2.53 & 2.98 & - \\
\hline
\end{tabular}

River sand was taken as a FA, which is delimiting to zone II grading accordance with IS: 383-1970 [9] with 2.60 of specific gravity and 2.60 of fine modulus. $12 \mathrm{~mm}$ of size crushed granite stones confirming to IS: 2386 (Part -I) 1963 [12] was used as CA with 2.91 of specific gravity and 6.60 of fineness modulus.
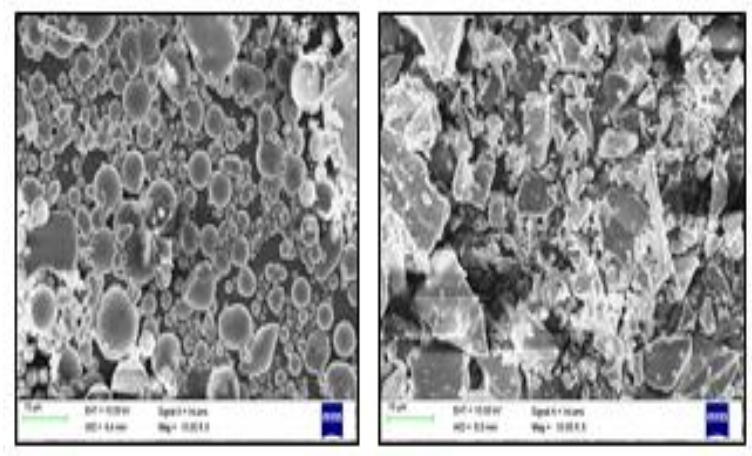

Fig. 1\&2.Morphology of Fly ash and GGBS.

In this research, low carbon hook end steel fibers with yield strength of $650 \mathrm{MPa}$ was used, and Table II shows the details of Hook End steel fibers.

Table- II: Details of Hook End Steel Fibers

\begin{tabular}{|l|l|l|}
\hline Length $(\mathrm{mm})$ & Diameter $(\mathrm{mm})$ & Aspect Ratio \\
\hline 35 & 0.75 & 45 \\
\hline 50 & 0.75 & 65 \\
\hline 60 & 0.75 & 80 \\
\hline
\end{tabular}

\section{EXPERIMENTAL PROCEDURE}

The mix design procedure of GPC for this research was conceded out based on the report presented by Wallah and Rangan [27]. The density of $2400 \mathrm{~kg} / \mathrm{m}^{3}$ was assumed for GPC, which is analogous to the control concrete. OPC was substituted by $10 \%$ of GGBS and $90 \%$ of fly ash to create the geopolymer concrete. The proportion between salty liquid to fly ash and activator solution arrangement was reserved as 0.4 and 2.5 correspondingly. Additional water and Super plasticizer were supplementary to the blend by $15 \%$ and $3 \%$ correspondingly by the heaviness of binder materials to enhance the workability of fresh concrete. Absolutely 10 blends, one control blend without steel fibers, and nine blends in with steel fibers were readied. Table III introduces the blend for $1 \mathrm{~m}^{3}$ of concrete for various extents of materials. This present research was intended to deliver a geopolymer concrete made with fly debris and GGBS what's more with steel fibers in various angle proportions and volume parts. The various volume portions of steel fibers were included by the level of $0.25 \%, 0.50 \%$, and $0.75 \%$ to the concrete, with viewpoint proportions of 45, 65, and 80 .

GPC specimens were restored under ambient and heat curing and tried for compressive strength. The samples were reserved in a hot oven for $24 \mathrm{hrs}$ at a heat of $60^{\circ} \mathrm{C}$ for heat curing. At various age of three, Seven and 28 days, the compressive strength was tried in heat curing, Twenty and 56 days for tensile and flexural, and 28 curing days for impact potency under ambient curing. At least three samples were cast for every mix for the purpose of finding the properties. Next to mixing process, $100 \mathrm{~mm}$ side cubes, $100 \mathrm{~mm}$ size with $500 \mathrm{~mm}$ length prisms, dia of 150 , and 300 $\mathrm{mm}$ height cylinders and dia of $150 \mathrm{~mm}$ and height of $65 \mathrm{~mm}$ discs were made to find the compressive, tensile, flexural and impact strengths. 
Table- III: Mix for $1 \mathrm{~m}^{3}$ of concrete for different proportions of materials in $\mathrm{kg}$

\begin{tabular}{|l|l|l|l|l|l|l|l|l|l|l|l|}
\hline Mix Id. & $\begin{array}{l}\text { Aspect } \\
\text { ratio }\end{array}$ & $\begin{array}{l}\text { \% of } \\
\text { fiber }\end{array}$ & $\begin{array}{l}\text { Fly } \\
\text { Ash }\end{array}$ & GGBS & FA & $\mathrm{CA}$ & $\mathrm{NaOH}$ & $\mathrm{Na}_{2} \mathrm{SiO}_{3}$ & Water & SP & $\begin{array}{l}\text { Steel } \\
\text { fiber }\end{array}$ \\
\hline $\mathrm{GC}$ & - & - & 354.9 & 39.4 & 554.4 & 1294 & 45.1 & 112.6 & 59.1 & 11.8 & - \\
\hline $\begin{array}{l}\mathrm{F} 1- \\
\mathrm{AR}_{45} \mathrm{~V}_{0} \\
.25\end{array}$ & 45 & 0.25 & 354.9 & 39.4 & 554.4 & 1294 & 45.1 & 112.6 & 59.1 & 11.8 & 19.63 \\
\hline $\begin{array}{l}\text { F1- } \\
\mathrm{AR}_{65} \mathrm{~V}_{0} \\
.50\end{array}$ & 65 & 0.50 & 354.9 & 39.4 & 554.4 & 1294 & 45.1 & 112.6 & 59.1 & 11.8 & 39.25 \\
\hline $\begin{array}{l}\mathrm{F} 1- \\
\mathrm{AR}_{80} \mathrm{~V}_{0} \\
.75\end{array}$ & 80 & 0.75 & 354.9 & 39.4 & 554.4 & 1294 & 45.1 & 112.6 & 59.1 & 11.8 & 58.88 \\
\hline $\begin{array}{l}\mathrm{F} 2- \\
\mathrm{AR}_{45} \mathrm{~V}_{0} \\
.25\end{array}$ & 45 & 0.25 & 354.9 & 39.4 & 554.4 & 1294 & 45.1 & 112.6 & 59.1 & 11.8 & 19.63 \\
\hline $\begin{array}{l}\mathrm{F} 2- \\
\mathrm{AR}_{65} \mathrm{~V}_{0} \\
.50\end{array}$ & 65 & 0.50 & 354.9 & 39.4 & 554.4 & 1294 & 45.1 & 112.6 & 59.1 & 11.8 & 39.25 \\
\hline $\begin{array}{l}\mathrm{F} 2- \\
\mathrm{AR}_{80} \mathrm{~V}_{0} \\
.75\end{array}$ & 80 & 0.75 & 354.9 & 39.4 & 554.4 & 1294 & 45.1 & 112.6 & 59.1 & 11.8 & 58.88 \\
\hline $\begin{array}{l}\mathrm{F} 3- \\
\mathrm{AR}_{45} \mathrm{~V}_{0} \\
.25\end{array}$ & 45 & 0.25 & 354.9 & 39.4 & 554.4 & 1294 & 45.1 & 112.6 & 59.1 & 11.8 & 19.63 \\
\hline $\begin{array}{l}\mathrm{F} 3- \\
\mathrm{AR}_{65} \mathrm{~V}_{0} \\
.50\end{array}$ & 65 & 0.50 & 354.9 & 39.4 & 554.4 & 1294 & 45.1 & 112.6 & 59.1 & 11.8 & 39.25 \\
\hline $\begin{array}{l}\mathrm{F} 3- \\
\mathrm{AR}_{80} \mathrm{~V}_{0} \\
.75\end{array}$ & 80 & 0.75 & 354.9 & 39.4 & 554.4 & 1294 & 45.1 & 112.6 & 59.1 & 11.8 & 58.88 \\
\hline
\end{tabular}

\section{TESTING OF SPECIMENS}

The compaction factor test was performed to find out the flow nature of GPC in fresh stage. The compressive test was made on the cube specimens according to test standard IS $516-1959$ [10]. The split tensile test was carried out on the cylindrical specimen according to test standard IS 5816 1999 [11]. The flexural test was tested according to test standard IS 516 - 1959 [10], and impact test was performed on the disc specimen according to standard ACI 544.2R$89[25]$.

\section{TEST RESULTS AND DISCUSSIONS}

\section{A. Workability}

It is essential to verify the flow nature of GPC in a fresh stage due to its high viscosity. The workable property of GPC was tested using the compaction factor apparatus to find the compaction test by incorporating different volume fraction (Vr) and aspect ratios (Ar) of Hook End steel fibers with concrete.

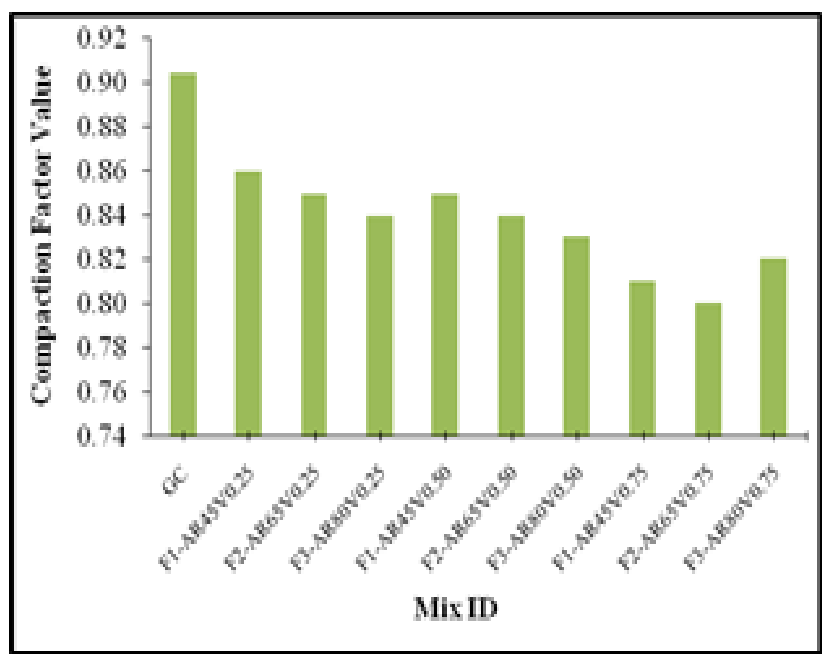

Fig. 3.Compaction factor results.

Figure 3 illustrated the influence of steel fibers and superplasticizer in the GPC mix. The compaction factor value of control GPC and fiber-reinforced geopolymer concrete lies in between 0.82 to 0.90 . The test result revealed that the augment in volume fraction and aspect ratio of hook end steel fibers outcome in a decrease in workability because mix becomes it's stiffer than control geopolymer concrete mix.

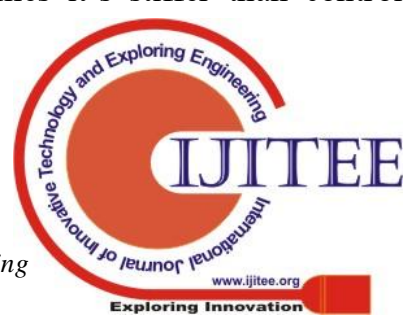




\section{EFFECT OF ASPECT RATIO AND VOLUME FRACTION OF STEEL FIBERS IN STRENGTH PROPERTIES OF GEOPOLYMER CONCRETE}

\section{B. Compressive strength Test}

Compressive strength development of GPC without and with hook end steel fibers with different volume fractions and aspect ratios under different curing exposures at different ages is shown in Figure 4 and Figure 5. The earlier studies reported that the rate of hydration prejudiced by the category of binders included. The setting time of concrete depends upon calcium content present in it [23]. In this investigation, the partially added GGBS with fly ash enhances the setting time of GPC in exposed to ambient curing condition. The influence of (Ar) and ( $\mathrm{Vr})$ of steel fibers on GPC mix were also discussed. The specimen made with $10 \%$ of GGBS and $90 \%$ of FA mix was kept as control specimen in this present study. The test results point out that adding up of hook end steel fibers improves compressive strength at all the ages. The increase in aspect ratio of hook end steel fibers increases the compressive strength of GPC. The highest strength of (41.68 MPa) was attained for F3$\mathrm{AR}_{80} \mathrm{~V}_{0.75}$ specimen model. Compressive strength of $\mathrm{F} 3$ $\mathrm{AR}_{80} \mathrm{~V}_{0.75}$ concrete specimen increases by $33 \%$ when compared with GC specimen.

It was noticed that the strength achieved at twenty days in ambient temperature curing was nearly

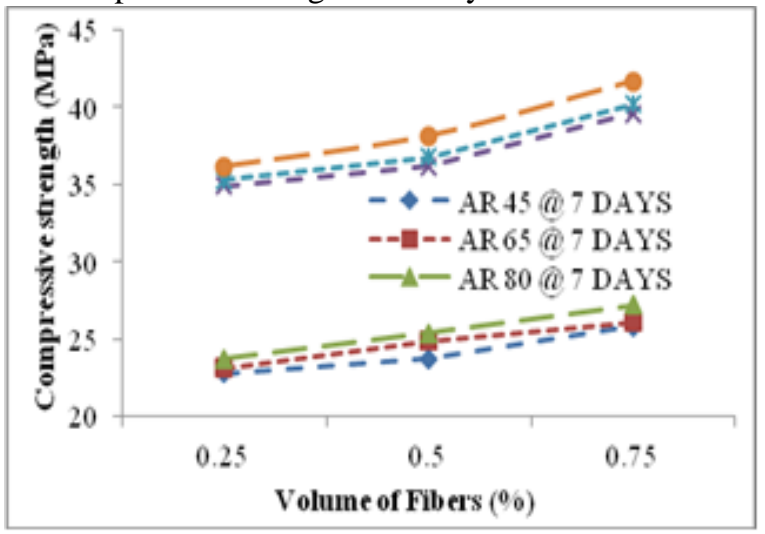

Fig. 4.Compressive strength of FRGPC specimens in ambient curing.

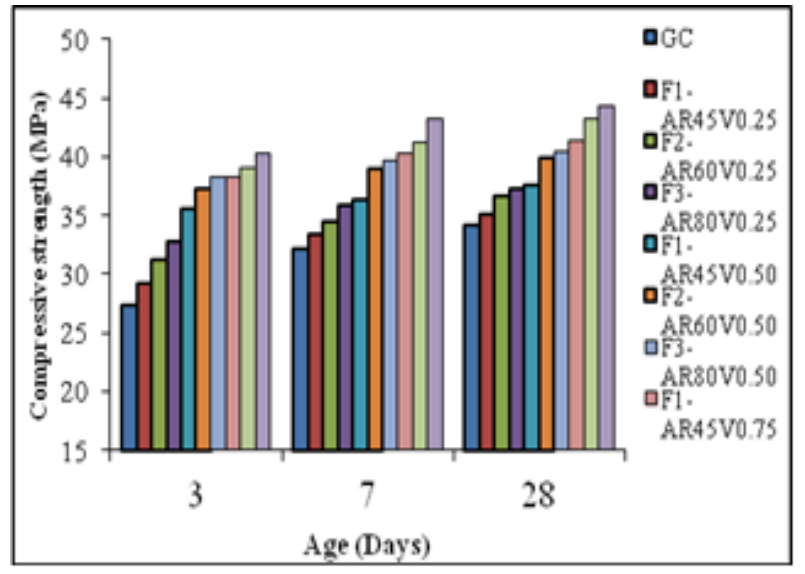

Fig. 5.Compressive strength of FRGPC specimens in Heat Curing.

similar strength attained in three days in heat based curing. Strength development of GC and fibere reinforced GPC specimens under ambient curing in the age of twenty days was like to the strength attained at twenty days in heat curing. The compressive strength was attained at premature ages in heat based curing because during the heat curing, it facilitates superior dissolution action of $\mathrm{Al}$ and $\mathrm{Si}$ ions which forming tough polymer fetter as reported [16].

\section{Split Tensile strength Test}

Split tensile strength developments of GPC without and with hook end steel fibers are illustrated here Figure 6. Similar to the compressive strength of fiber-reinforced GPC, tensile strength also gets augmented with raise in aspect ratios (Ar) and various volume fractions of hook end steel fibers when contrast to control GPC specimen. Split tensile strength of $\mathrm{F} 3-\mathrm{AR}_{80} \mathrm{~V}_{0.75}$ increases by $98 \%$ when compared to control GC specimen at the age of twenty days.

At 28 days, for an aspect ratio of 45, the enhancement of tensile strength was identified to be $14 \%, 24 \%$, and $27 \%$ by the volume fractions of $0.25 \%, 0.50 \%$, and $0.75 \%$ respectively. For an aspect ratio of 65 , the enhancement of tensile strength was identified to be $16 \%, 54 \%$, and $62 \%$ for the volume fractions of $0.25 \%, 0.50 \%$, and $0.75 \%$, respectively. For an aspect ratio of 80 , the amplify in tensile strength was found to be $28 \%, 67 \%$, and $98 \%$ for the volume fractions of $0.25 \%, 050 \%$, and $0.75 \%$, respectively.

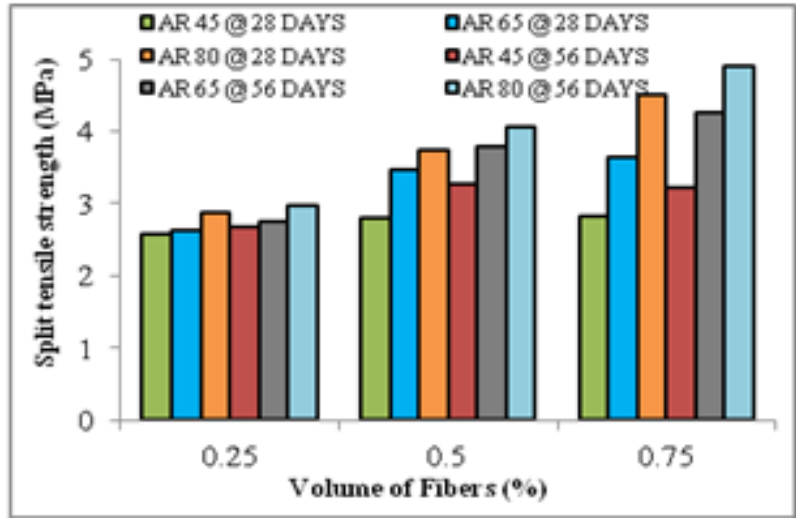

Fig. 6.Split tensile strength of FRGPC specimens.

\section{Flexural strength}

Flexural strength developments of GPC without hook end steel fibers and inclusion of hook end steel fibers are illustrated here Figure 7. Similar to split tensile strength of fiber-reinforced GPC, flexural strength also gets increased with enhance in aspect ratios and various volume fractions of hook end steel fibers when matched to control GPC specimen. Flexural strength of $\mathrm{F} 3-\mathrm{AR}_{80} \mathrm{~V}_{0.75}$ increases by $64 \%$ when compared to GC specimen at the age of 28 days.

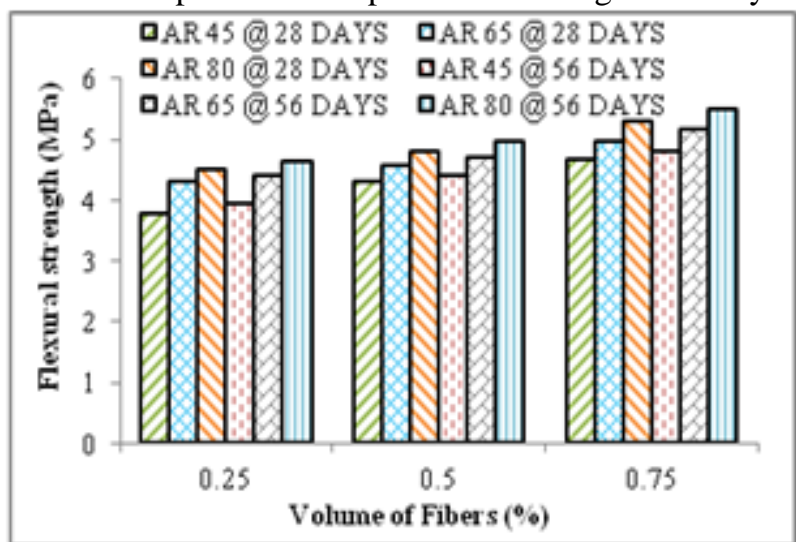

Fig. 7.Flexural strength of FRGPC specimens.

Blue Eyes Intelligence Engineering

\& Sciences Publication

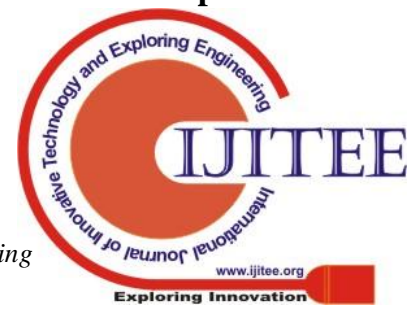


At 28 days of age, for an aspect ratio of 45 , the flexural strength was increase by $17 \%, 32 \%$, and $43 \%$ with the volume fractions of $0.25 \%, 0.50 \%$, and $0.75 \%$ respectively. For an aspect ratio of 65 , the increase in strength was $32 \%$, $40 \%$, and $53 \%$ with the volume fractions of $0.25 \%, 0.50 \%$, and $0.75 \%$, respectively. For an aspect ratio of 80 , the increase in strength was $38 \%, 48 \%$, and $63 \%$ for the volume fractions percentages of $0.25,0.50$, and 0.75 correspondingly.

\section{E. Impact strength}

Impact resistance of GPC with and without hook end steel fibers is exemplified herewith Figure 8. Similar to the strength properties of fiber-reinforced GPC, impact strength also gets enhanced with incremental in various aspect ratios and various volume fractions of hook end steel fibers when correlated to control GPC specimen. Impact strength of F3$\mathrm{AR}_{80} \mathrm{~V}_{0.75}$ increases by $141 \%$ when compared to control GC specimen. For an aspect ratio of 45 , the increase in impact strength was found to be $77 \%, 87 \%$, and $100 \%$ for the volume fractions percentages of $0.25,0.50$, and 0.75 correspondingly. For an aspect ratio of 65 , the increase in impact strength was found to be $101 \%, 114 \%$ and $122 \%$. For an aspect ratio of 80 , the increase in impact strength was found to be $123 \%, 130 \%$, and $141 \%$.

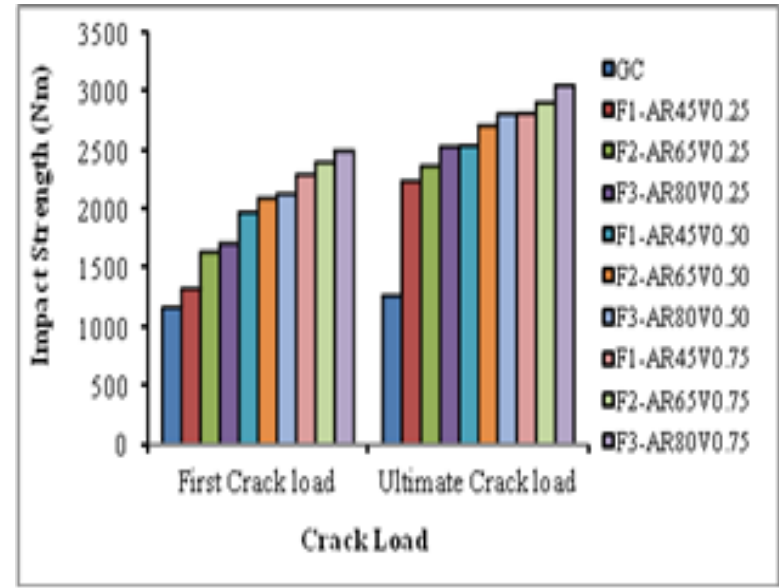

Fig. 8.Impact strength of FRGPC specimens.

It was pragmatic that the add to in aspect ratio and various volume fractions of hook end steel fibers in GC enhances the impact capacity of concrete owed to of its ability of absorb the kinetic energy and delaying the formation of cracks and failure [24].

\section{F. Scanning electron microscope (SEM/EDAX)}

It was carried out on GC specimens to identify and to verify the changes in the internal microstructure because of the different curing conditions. It also characterizes the bonding and reaction of concrete in the geopolymer matrix. The bonding is the main character in producing strong geopolymer matrix and plays a role by increasing its strength. The morphological changes of GC specimens under various curing ages at twenty days was illustrated in Figure $9 \& 10$. The SEM image of the ambient cured GC specimen demonstrates that the presence of crystalline phases are very much clear, and also some unreacted FA particles presence in structure after 28 days of curing (Fig.9).
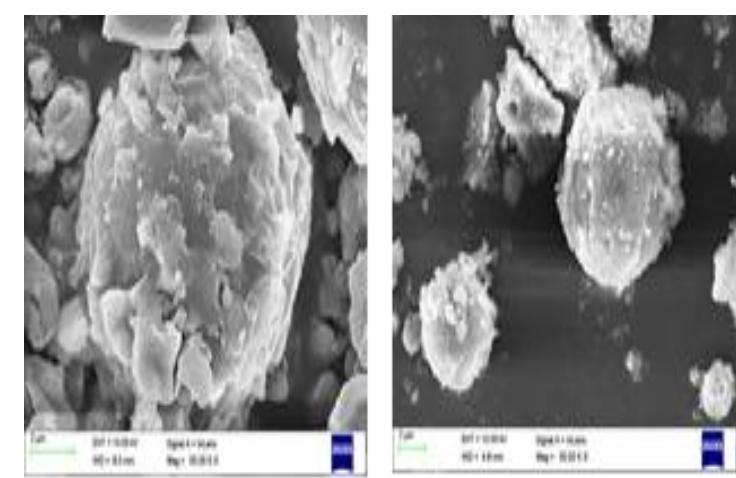

Fig. 9 \& 10. The morphological changes of ambient cured GC specimen and Heat cured specimen.

Close observation was made in Fig.10, and it reveals that in heat curing, the particles become denser in structure. The image shows that the high strength is correlated to the compact microstructure. Combined with the compressive strength and microstructure as analyzed above, it can be evidenced that the mechanical properties of GC closely relate to bonding and density of materials present in it.
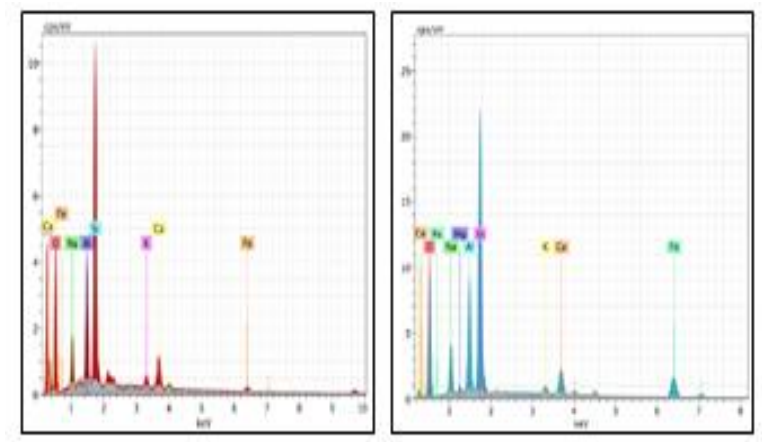

Fig. 11\&12.EDS Analysis of ambient cured and heat cured GC specimen.

The EDS analysis of the different cured GC specimen was studied, and the weight of significant elements present on it was calculated. In the ambient cured GC specimen, the elements such as $\mathrm{Si}$ 10.6, Al 5, Na 1.75, O 5.2, and Ca 5.3 were present, as shown in Fig.11. In heat-cured GC specimens, the elements such as Si 22, Al 11, O 11, Na 4, $\mathrm{Mg}$ 11, and $\mathrm{Fe}$ 1.5, which were present in higher percentage when compared with GC in the structure because of heat curing, were seen as shown in Fig.12. It was observed that at the time of heat curing in the specimen, it reacts with the elements in higher percentage and in particular, with silica.

\section{CONCLUSIONS}

The present research examined the influence of various aspect ratios and various volume fractions of hook end steel fibers in geopolymer concrete under different curing conditions. With respect to the results acquired from the investigational work, the subsequent conclusions were drawn.

1) Limitations exist in practical application in GPC is setting time of concrete - this problem resolved by the adding up of GGBS content with FA in this study. The 


\section{EFFECT OF ASPECT RATIO AND VOLUME FRACTION OF STEEL FIBERS IN STRENGTH PROPERTIES OF GEOPOLYMER CONCRETE}

addition of $10 \%$ of GGBS with $90 \%$ of FA consequences in the diminution of setting time of GPC because of the existence of a soaring volume of calcium content.

2) Test results exposed that enhance in various volume fractions and various aspect ratios of Hook type steel fibers diminish the workability of concrete.

3) From the investigation, it was found that the higher amount of aspect ratios and higher amount of volume of hook end steel fibers in concrete increases the compressive strength in ambient curing at all the ages, a slight reduce in strength in heat curing when matched to ambient cured specimens.

4) The concrete achieved higher strength in heat curing with in the small duration due to long geopolymerization progression. The fiber added GPC mixes acquiesce superior strength in both curings.

5) Tensile, Flexural, and Impact perfomance of concrete increased with an improvement in strength of GC and FRGPC. Microstructure analysis of structure by SEM and EDS, it was noticed on the presence of dense material led to increase in the mechanical properties and there is a correlation between bonding and curing type.

6) The study recommended that addition of hook type steel fibers in higher volume fractions ( $\mathrm{Vr}$ ) and aspect ratio (Ar) with 10\% of GGBS and $90 \%$ of Flay ash enhances the mechanical properties.

\section{REFERENCES}

1. Abdollahnejad, Z., Pacheco-Torgal, F., Félix, T., Tahri, W., \& Aguiar, J. B. (2015). Mix design, properties and cost analysis of fly ash-based geopolymer foam. Construction and Building Materials, 80, 18-30.

2. Abdulkareem, O. A., Al Bakri, A. M., Kamarudin, H., Nizar, I. K., \& Ala'eddin, A. S. (2014). Effects of elevated temperatures on the thermal behavior and mechanical performance of fly ash geopolymer paste, mortar and lightweight concrete. Construction and building materials, 50, 377-387.

3. Aliabdo, A. A., Elmoaty, A. E. M. A., \& Salem, H. A. (2016). Effect of cement addition, solution resting time and curing characteristics on fly ash based geopolymer concrete performance. Construction and building materials, 123, 581-593.

4. Davidovits, J. (1989). Geopolymers and geopolymeric materials. Journal of Thermal Analysis and Calorimetry, 35(2), 429-441.

5. Deevasan, K. K., \& Ranganath, R. V. (2010). Geopolymer concrete using industrial byproducts. Proceedings of the Institution of Civil Engineers-Construction Materials, 164(1), 43-50.

6. Ganesan, N., Abraham, R., \& Raj, S. D. (2015). Durability characteristics of steel fibre reinforced geopolymer concrete. Construction and Building Materials, 93, 471-476.

7. Hardjito, D., Wallah, S. E., Sumajouw, D. M. J., \& Rangan, B. V. (2005, August). Introducing fly ash-based geopolymer concrete: manufacture and engineering properties. In 30th conference on our world in concrete \& structures (pp. 23-24).

8. Ilkentapar, S., Atiş, C. D., Karahan, O., \& Avşaroğlu, E. G. (2017). Influence of duration of heat curing and extra rest period after heat curing on the strength and transport characteristic of alkali activated class F fly ash geopolymer mortar. Construction and Building Materials, 151, 363-369.
9. Islam, A., Alengaram, U. J., Jumaat, M. Z., Ghazali, N. B., Yusoff, S., \& Bashar, I. I. (2017). Influence of steel fibers on the mechanical properties and impact resistance of lightweight geopolymer concrete. Construction and Building Materials, 152, 964-977.

10. Khan, M. Z. N., Hao, Y., \& Hao, H. (2016). Synthesis of high strength ambient cured geopolymer composite by using low calcium fly ash. Construction and Building Materials, 125, 809-820.

11. Kusbiantoro, A., Nuruddin, M. F., Shafiq, N., \& Qazi, S. A. (2012). The effect of microwave incinerated rice husk ash on the compressive and bond strength of fly ash based geopolymer concrete. Construction and Building Materials, 36, 695-703.

12. Reed, M., Lokuge, W., \& Karunasena, W. (2014). Fibrereinforced geopolymer concrete with ambient curing for in situ applications. Journal of materials science, 49(12), 4297-4304.

13. Memon, F. A., Nuruddin, M. F., Demie, S., \& Shafiq, N. (2011). Effect of curing conditions on strength of fly ashbased self-compacting geopolymer concrete. Int. J. Civ. Environ. Eng, 3, 183-186.

14. Al-mashhadani, M. M., Canpolat, O., Aygörmez, Y., Uysal, M., \& Erdem, S. (2018). Mechanical and microstructural characterization of fiber reinforced fly ash based geopolymer composites. Construction and Building Materials, 167, 505-513.

15. Nath, S. K., Maitra, S., Mukherjee, S., \& Kumar, S. (2016). Microstructural and morphological evolution of fly ash based geopolymers. Construction and Building Materials, 111, 758-765.

16. Nguyen, K. T., Ahn, N., Le, T. A., \& Lee, K. (2016). Theoretical and experimental study on mechanical properties and flexural strength of fly ash-geopolymer concrete. Construction and Building Materials, 106, 6577.

17. Nikolić, V., Komljenović, M., Baščarević, Z., Marjanović, N., Miladinović, Z., \& Petrović, R. (2015). The influence of fly ash characteristics and reaction conditions on strength and structure of geopolymers. Construction and Building Materials, 94, 361-370.

18. B. Prabu, A. Shalini, J.S. Kishore Kumar, "Rice husk ash based geopolymer concrete - A Review", Chemical Science Review and Letters, 2014, 3(10), pp. 288-294.

19. B. Prabu, R. Kumutha, K. Vijai, "Effect of fibers on the mechanical properties of fly ash and GGBS based geopolymer concrete under different curing conditions", Indian Journal of Engineering and Materials Sciences, 2017, 24: pp. 5-12.

20. Singh, B., Rahman, M. R., Paswan, R., \& Bhattacharyya, S. K. (2016). Effect of activator concentration on the strength, ITZ and drying shrinkage of fly ash/slag geopolymer concrete. Construction and Building Materials, 118, 171-179..

21. Soutsos, M., Boyle, A. P., Vinai, R., Hadjierakleous, A., \& Barnett, S. J. (2016). Factors influencing the compressive strength of fly ash based geopolymers. Construction and Building Materials, 110, 355-368.

22. P. Surendra Shah, "Measurements of properties of fiber reinforced concrete". ACI Materials Journal, 1988, 85: pp. 583-593.

23. Vijai, K., Kumutha, R., \& Vishnuram, B. G. (2012). Effect of inclusion of steel fibres on the properties of geopolymer concrete composites. 
24. S.E. Wallah, B.V. Rangan, "Low-Calcium Fly AshBased Geopolymer Concrete: Long-Term Properties", Research Report GC 2, Curtin University of Technology, Australia, 2006.

25. Wardhono, A., Gunasekara, C., Law, D. W., \& Setunge, S. (2017). Comparison of long term performance between alkali activated slag and fly ash geopolymer concretes. Construction and Building materials, 143, 272-279.

26. Li, W., \& Xu, J. (2009). Mechanical properties of basalt fiber reinforced geopolymeric concrete under impact loading. Materials Science and Engineering: A, 505(1-2), 178-186.

27. Li, Z., Zhang, Y., \& Zhou, X. (2005). Short fiber reinforced geopolymer composites manufactured by extrusion. Journal of materials in civil engineering, 17(6), 624-631.

\section{AUTHORS PROFILE}

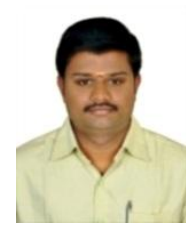

B.Prabu is the Assistant Professor, Department of Civil Engineering, Sona College of Technology, Salem, India. He has authored about 25 papers in National and International journals and conferences. . He has guided about 15 UG projects and about 10 PG projects. He is a life time member in IEI (Institution of Engineers India) and ISTE (Indian Society for Technical Education).

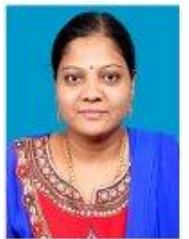

Dr.R.Kumutha working as Professor in the Civil Engineering Department, Sethu Institute of Technology, Kariapatti, India. She has published more than 37 research articles in different International and National Journals and 23 papers in National and International conferences. She has received grants from various funding agencies like DST, TNSCST, NPCIL, and AICTE.

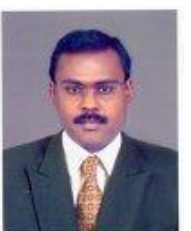

Dr.K.Vijai is working as Professor in Civil Engineering Department, St. Joseph College of Engineering, Chennai, India. He has published more than 30 research articles in various National and International Journals. He has guided more than 15 PG projects and about 25 UG projects. He is a life time member in ISTE. 